\title{
Spatio-temporal variability in fish-induced predation mortality on plankton: A simulation approach using a coupled trophic model of the Benguela ecosystem
}

\author{
M. Travers ${ }^{a,{ }^{*}}$, Y.-J. Shin ${ }^{a}$
}

${ }^{a}$ IRD Institut de Recherche pour le Développement, CRH Centre de Recherche Halieutique Méditerranéenne et Tropicale, Avenue Jean Monnet, BP 171, 34203 Sète cedex, France

* Corresponding author : M. Travers, Tel.: +33 4995732 52; fax: +33 4995732 95, email address : travers@ird.fr, $\underline{\text { Morgane.Travers@ifremer.fr }}$

\begin{abstract}
:
We investigate the potential predation pressure that would affect plankton communities spatially and seasonally using a coupled model, where fish-induced predation mortality is explicit. In the southern Benguela ecosystem, the fish model OSMOSE is forced by a biogeochemical model providing plankton prey fields. We analyse the resulting potential predation mortality rate on copepods. Spatially, this mortality rate is higher on the South coast (Agulhas bank) than on the West coast (upwelling zone), reflecting a lower plankton concentration compared to food requirement for fish. Temporally, fish-induced predation mortality decreases at the beginning of the upwelling season, due to a rapid increase of plankton concentration combined with a lag in the subsequent increase of fish biomass. Such strong spatio-temporal patterns in fish-induced predation mortality encourage the development of two-ways coupling between fish and plankton models for better representing the dynamics of the southern Benguela food web.
\end{abstract}




\section{Introduction}

High trophic level (HTL) models such as larval individual-based models (Hermann et al., 2001) and whole life cycle models of fish (Rose et al., 2007; Lehodey et al., 2003) can be forced by plankton distributions. These prey fields are provided either directly from observations or from low trophic level (LTL) models (Hermann et al., 2001; Rose et al., 2007). In the latter case, the link between HTL and LTL models is often a one-way coupling or forcing where no feedbacks are taken into account. The aim of this study is to quantify what would be the feedback of fish predation on plankton dynamics in the southern Benguela upwelling ecosystem. We force a HTL model (OSMOSE) with the outputs of a LTL model (ROMS- $\mathrm{N}_{2} \mathrm{P}_{2} \mathrm{Z}_{2} \mathrm{D}_{2}$ ) and we analyse the resulting fish-induced predation on plankton.

\section{Materials and methods}

\subsection{LTL model: ROMS- $\mathrm{N}_{2} \mathrm{P}_{2} \mathrm{Z}_{2} \mathrm{D}_{2}$}

The Regional Ocean Modelling Systems (ROMS) is a 3 dimensional hydrodynamics model which has been applied to the Benguela ecosystem (Penven et al., 2001). It has been coupled to a $\mathrm{N}_{2} \mathrm{P}_{2} \mathrm{Z}_{2} \mathrm{D}_{2}$ model (Koné et al., 2005), a biogeochemical model of two compartments of nutrients $(\mathrm{N})$, phytoplankton $(P)$, zooplankton $(Z)$ and detritus (D). This biogeochemical model represents processes of uptake, predation, growth, excretion, egestion, mortality and sinking (Figure 1). Each plankton compartment can be assimilated to a functional group which is characterized by a specific size range: flagellates $(2-20 \mu \mathrm{m})$ and diatoms $(20-200 \mu \mathrm{m})$ represent the two phytoplankton compartments and ciliates $(20-200 \mu \mathrm{m})$ and copepods $(200-2000 \mu \mathrm{m})$ represent respectively the micro-zooplankton and the mesozooplankton.

\subsection{HTL model: Osmose}

OSMOSE (Shin and Cury, 2001, 2004) is a 2 dimensional individual-based model representing the whole life cycle of several species of fish. It models processes of growth, predation, reproduction, natural and starvation mortalities (Figure 1, details in Appendix A). The main assumption is that predation is opportunistic and size-based constrained, and therefore occurs when there are both spatio-temporal co-occurrence and size-adequacy between a predator and its prey (determination of a minimum and a maximum predator to prey size ratio, supplementary Figure S1). Fish schools are considered to be able to eat annually no more than 3.5 grams of food per body gram (Shin and Cury 2001). Among the edible biomass of prey, a predator eats uniformly on prey, proportionally to their biomass, until it reaches satiety or depletes all prey available. A predation efficiency is computed from the biomass of prey eaten over the maximum ration, and serves to determine the growth of fish and possible starvation mortality. The Benguela application represents the dynamics of twelve fish species from small pelagic fish to large demersal fish in the 1990s (Shin et al., 2004; Travers et al., 2006). For the purpose of this study, we reduced the initial six months time step to monthly, which allows to force the model with seasonal plankton concentrations.

\subsection{Forcing of the HTL model by the LTL model}

In OSMOSE, fish were initially divided into two groups, piscivorous or non-piscivorous individuals, according to their taxonomy and age. Piscivorous fish predate on other explicitly modelled fish whereas the biomass of non-piscivorous fish was only constrained by an upper limit: the carrying capacity of the system. Forcing OSMOSE with ROMS- $N_{2} P_{2} Z_{2} D_{2}$ allows to replace this carrying capacity parameter by an explicit amount of plankton food available for non-piscivorous fish. In the present version of the model, each fish individual can predate on a combination of other 
fish, phytoplankton, and zooplankton (Figure 1), provided that the prey has a suitable size and is present in the same cell than the predator during the same time step. Predation mortality is explicit in the fish model and uniformly applied to the co-occurring organisms having a size comprised between the minimum and the maximum size edible, without taxonomy consideration.

To deal with the difference of spatial grids used in each model, the prey field (in mmolN.m ${ }^{-3}$ ) is first vertically integrated over the upper $100 \mathrm{~m}$. Plankton concentrations are averaged over the month and used as input of OSMOSE at each time step. The concentration of plankton is transformed from nitrogen concentration $\left(\mathrm{mmolN} . \mathrm{m}^{-2}\right)$ into wet biomass per square meter using classical conversion factors.

The calibration of the OSMOSE model forced by prey fields was undertaken by allowing larval mortalities to vary in order to obtain the mean biomass of species in the range estimated for the 1990s (Shannon et al. 2003). In addition to biomass patterns, simulated size-based indicators display similar patterns as observed in the Benguela system. The only output presented in this study is the consumption of plankton by fish. Because of the model stochasticity, the results of 20 simulations are averaged. We calculate the potential predation mortality rate which would affect the plankton as the plankton biomass eaten at each time step divided by the available plankton biomass.

\section{Results}

The average fish-induced mortality rates depend directly on the size range of plankton prey: 0.002 month $^{-1}$ for the $2-20 \mu \mathrm{m}$ group (flagellates), 0.126 month $^{-1}$ for the $20-200 \mu \mathrm{m}$ group (diatoms and ciliates) and 0.362 month $^{-1}$ for the $200-2000 \mu \mathrm{m}$ group (copepods). These predation mortality rates represent respectively $0.25 \%, 14 \%, 16.8 \%$ and $24.13 \%$ of the global natural mortality rates used in the uncoupled version of ROMS- $\mathrm{N}_{2} \mathrm{P}_{2} \mathrm{Z}_{2} \mathrm{D}_{2}$. They are underestimates of actual natural mortality rates of plankton since other predators and other sources of mortality (e.g. senescence) are not taken into account in the simulations. In the following example, we focus on the spatiotemporal variability of the predation mortality rate induced by fish and we only present the results for the mesozooplankton group as it is the most affected by fish predation.

The simulations show a strong spatial heterogeneity of copepods predation mortality rate (Figure 2a). The predation mortality rate is higher on the Agulhas bank (South coast) than in the upwelling zone (West coast). In the southern area, fish-induced predation is stronger inshore than offshore, whereas this pattern is not observed in the upwelling area.

There is also a marked temporal variability of the predation rate on copepods (Figure 2b). We can particularly notice the low mortality rate during spring and early summer (September to December). The temporal variability is more attributable to the West and South-West part of the modelled area, but the reduced mortality rate at the end of the year is a general feature in the whole area.

\section{Discussion}

The South African West coast presents a low potential predation mortality rate on mesozooplankton. It is worth noting that the forcing prey field has a concentration in mesozooplankton two times higher on the West coast than on the South coast, so this high amount of available food would lead to a large consumption by fish, but to a relatively lower predation rate on mesozooplankton. Nevertheless, predation mortality rate on copepods appears to be locally strong in St Helena Bay, which is known to be a major nursery area for small pelagic fish (Hutchings et al., 1998).

The lower predation rate during spring and early-summer could be due either to a larger concentration of mesozooplankton for a constant food requirement of fish or to a lower food requirement for fish with a constant concentration of mesozooplankton. The upwelling season is more pronounced between September and March in the southern Benguela, leading to an increase 
of plankton concentration during this period. The increase of fish biomass occurs later in the year (Figure 2b), which explains the initial decrease of predation rate on mesozooplankton, followed by an increase in December.

The feedback induced by fish predation on plankton has been simulated by Megrey et al. (2007) by coupling a biogeochemical model and a whole life cycle fish model. Their study showed that the dynamics of both plankton and fish were affected by this density-dependent feedback, and that it could even cascade down to the phytoplankton level.

Biogeochemical models of plankton use a fixed mortality term for representing fish predation, which has a considerable effect on simulated dynamics (Edwards and Yool, 2000). Our simulations suggest that the mortality rate due to fish predation is highly variable over space and time in the southern Benguela ecosystem. Considering feedbacks between OSMOSE and ROMS$\mathrm{N}_{2} \mathrm{P}_{2} \mathrm{Z}_{2} \mathrm{D}_{2}$ models may therefore improve the simulated dynamics of plankton and subsequent responses of fish populations. In addition, implementing a two-ways coupling between HTL and LTL models would allow propagations of perturbations both up and down the food web for a better quantification of anthropogenic and climate effects on the dynamics of marine ecosystems (Travers et al. 2007).

\section{Aknowledgements}

The authors would like to thank the IGBP programs IMBER and GLOBEC as well as the European Union's 6th Framework Program Network of Excellence EUR-OCEANS for funding the symposium on "Parameterization of Trophic Interactions in Ecosystem Modelling", Cadiz, March 2007. This is a contribution to EUR-OCEANS Network of Excellence funded by the European Commission (contract FP6-511106). Morgane Travers was supported by a EUR-OCEANS scholarship. Yunne Shin was partly funded by the French ANR 'Chaloupe' project.

\section{References}

Edwards, A.M., Yool, A. (2000). The role of higher predation in plankton population models. Journal of Plankton Research, 22, 1085-1112.

Hermann, A., Hinckley, S., Megrey, B., Napp, J. (2001). Applied and theoretical considerations for constructing spatially explicit individual-based models of marine larval fish that include multiple trophic levels. ICES Journal of Marine Science, 58, 1030-1041

Hutchings, L., Barange, M., Bloomer S.F. et al. (1998) Multiple factors affecting anchovy recruitment in the spawning, transport and nursery areas. In: Benguela Dynamics. Impacts of Variability on Shelf-Sea Environments and their Living Resources. S.C. Pillar, C.L. Moloney, A.I.L. Payne and F.A. Shillington (eds) S. Afr. J. mar. Sci. 19:211-225.

Koné, V., Machu, E., Penven, P., Andersen, V., Garçon, V., Demarcq, H., Fréon, P. (2005). Modelling the primary and secondary productions of the Southern Benguela upwelling system: a comparative study through two biogeochemical models. Global Biogeochemical Cycles, 19, GB4021.

Lehodey, P., Chai, F. and Hampton, J. (2003). Modelling climate-related variability of tuna populations from a coupled ocean-biogeochemical-populations dynamics model. Fisheries Oceanography, 12, 483-494.

Megrey, B., Rose, K., Klumb, R., Hay, D., Werner, F., Eslinger, D., Smith, L. (2007). A bioenergetic/population dynamics model of Pacific herring (Clupea harengus pallasi) coupled to a lower trophic level nutrient-phytoplankton-zooplankton model: Dynamics, description, validation and sensitivity analysis. Ecological Modelling, 202, 144-164.

Penven, P., Roy, C., Lutjeharms, J.R.E., Colin de Verdière, A., Johnson, A., Shillington, F., Freon, P. and Brundrit, G., 2001. A regional hydrodynamic model of the Southern Benguela. S. Afr. J. Sci., 97: 472-476. 
Rose, K.A., Werner, F., Megrey, B.A., Aita, M.N., Yamanaka, Y., Hay, D. (2007). Simulated herring growth responses in the Northeastern Pacific to historic temperature and zooplankton conditions generated by the 3-dimensional NEMURO nutrient-phytoplankton-zooplankton model. Ecological Modelling, 202, 184-195.

Shannon, L.J., Moloney, C.L., Jarre, A., and Field, J.G. 2003. Trophic flows in the southern Benguela during the 1980s and 1990s. J. Mar. Syst. 39: 83-116.

Shin, Y.-J., Cury, P. (2001). Exploring fish community dynamics through size-dependent trophic interactions using a spatialized individual-based model. Aquatic Living Resources, 14, 65-80.

Shin, Y.-J., Cury, P. (2004). Using a individual-based model of fish assemblages to study the response of size spectra to changes in fishing. Canadian Journal of Fisheries and Aquatic Sciences, 61, 414-431.

Shin, Y., Shannon, L.J., Cury, P.M. (2004). Simulations of fishing effects on the Southern Benguela fish community using the individual-based model OSMOSE. Lessons from a comparison with Ecosim simulations. In Ecosystem approaches to fisheries in the Southern Benguela. Edited by L.J. Shannon, K.L. Cochrane, and S.C. Pillar. African Journal of Marine Science, 26, 95-114.

Travers, M., Shin, Y.-J., Shannon, L. Cury, P. (2006) Simulating and testing the sensitivity of ecosystem-based indicators to fishing in the southern Benguela ecosystem. Canadian Journal of Fisheries and Aquatic Sciences, 63, 943-956.

Travers, M., Shin, Y.-J., Jennings, S. Cury, P. (2007) Towards end-to-end models for investigating the effects of climate and fishing in marine ecosystems. Progress in Oceanography, 75, 751-770.

\section{Figures}

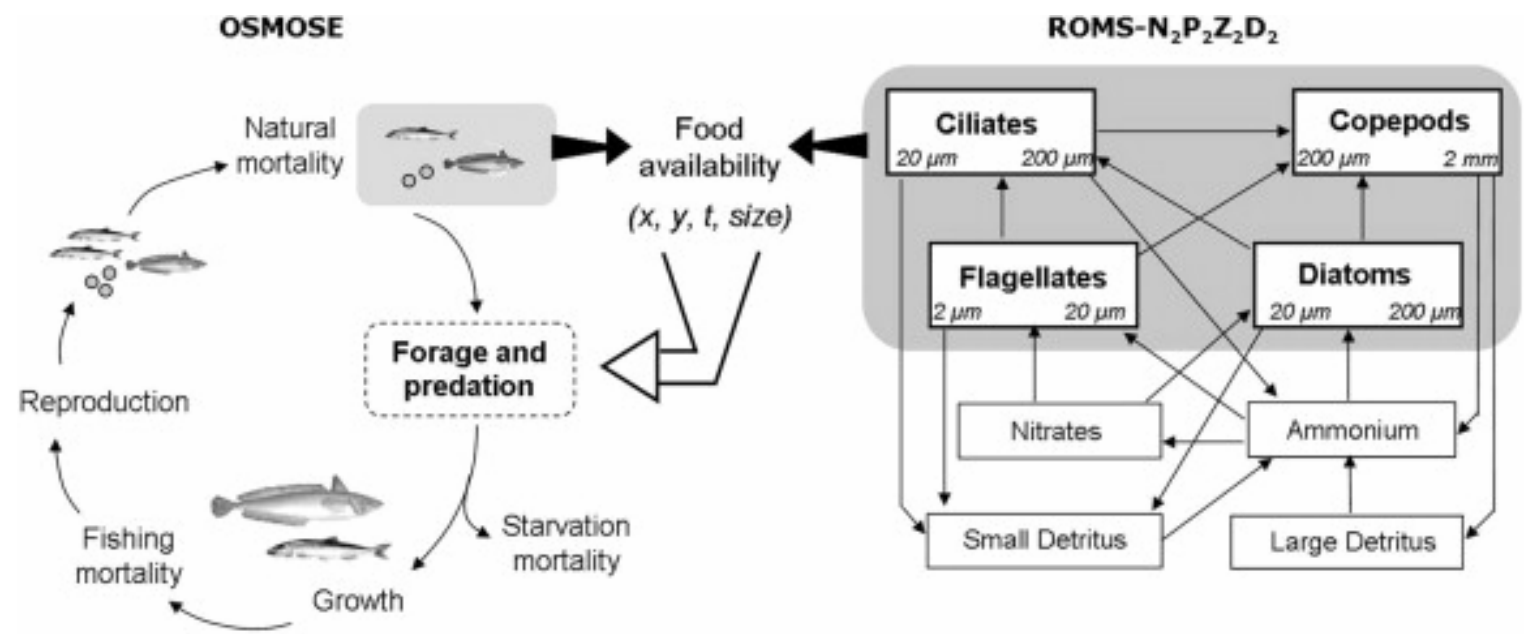

Figure 1: Principle of the forcing of Osmose model by the $\mathrm{N}_{2} \mathrm{P}_{2} \mathrm{Z}_{2} \mathrm{D}_{2}$ model. At each time step (t) and at each location $(x, y)$, the biomass of the living compartments of the biogeochemical model (phytoplankton and zooplankton) is used in Osmose for the predation process. In Osmose, fish can prey upon both plankton and fish, according to predator/prey size ratios and local prey availability. Growth and reproduction rate of fish depend on the amount of food consumed at each time step. 


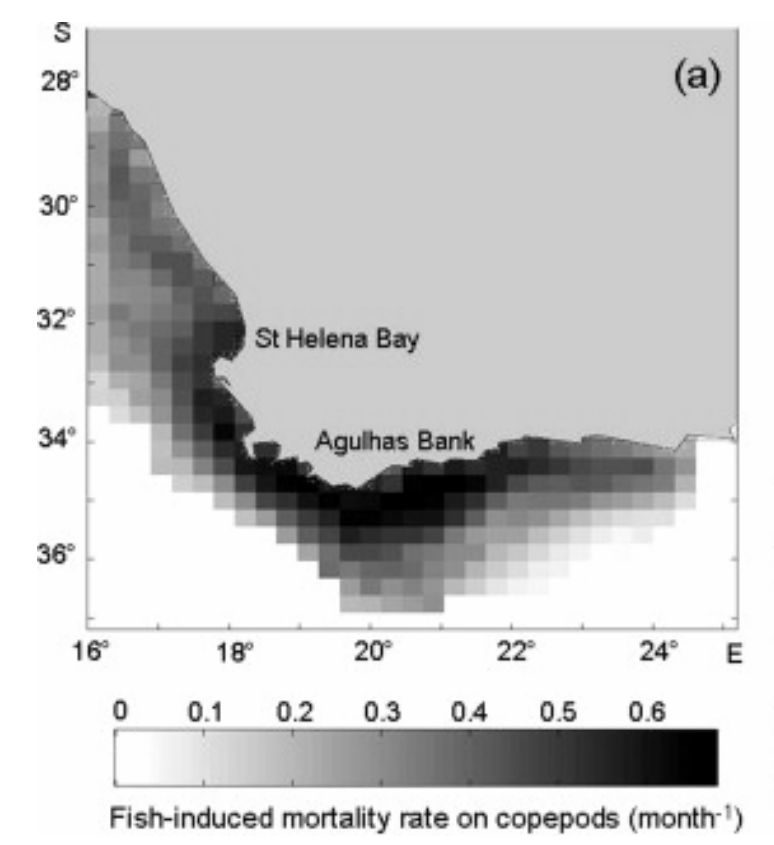

(b)

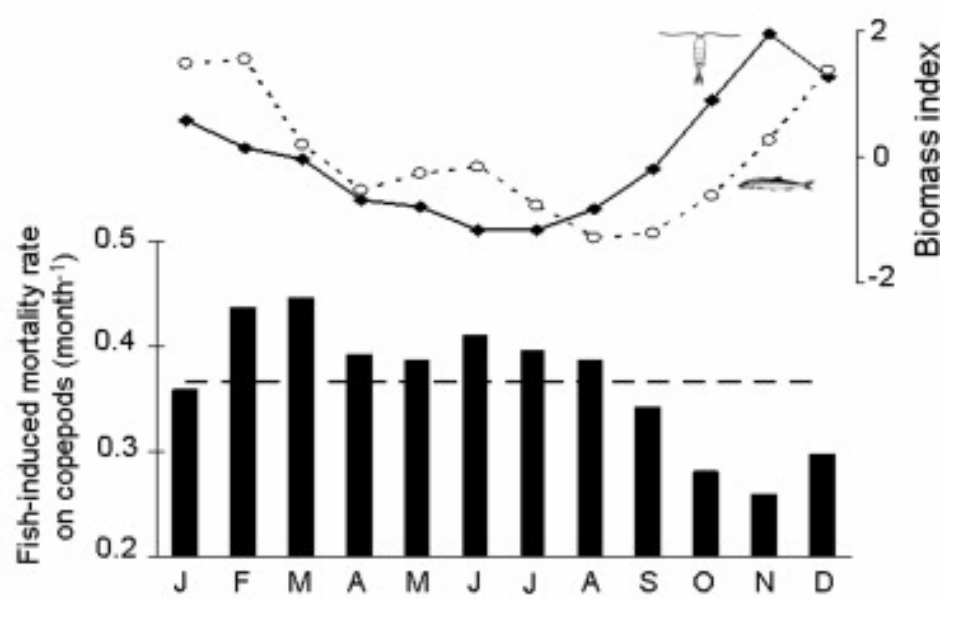

Figure 2: Potential predation mortality rate on mesozooplankton (in month ${ }^{-1}$ ). (a) spatial variability averaged over a year, (b) temporal variability averaged over fish spatial distribution. The mean annual mortality rate is shown on the histogram by the dashed line. The temporal dynamics of the normalized biomass of mesozooplankton (solid line) and of all fish (dashed line) are shown above the histogram.

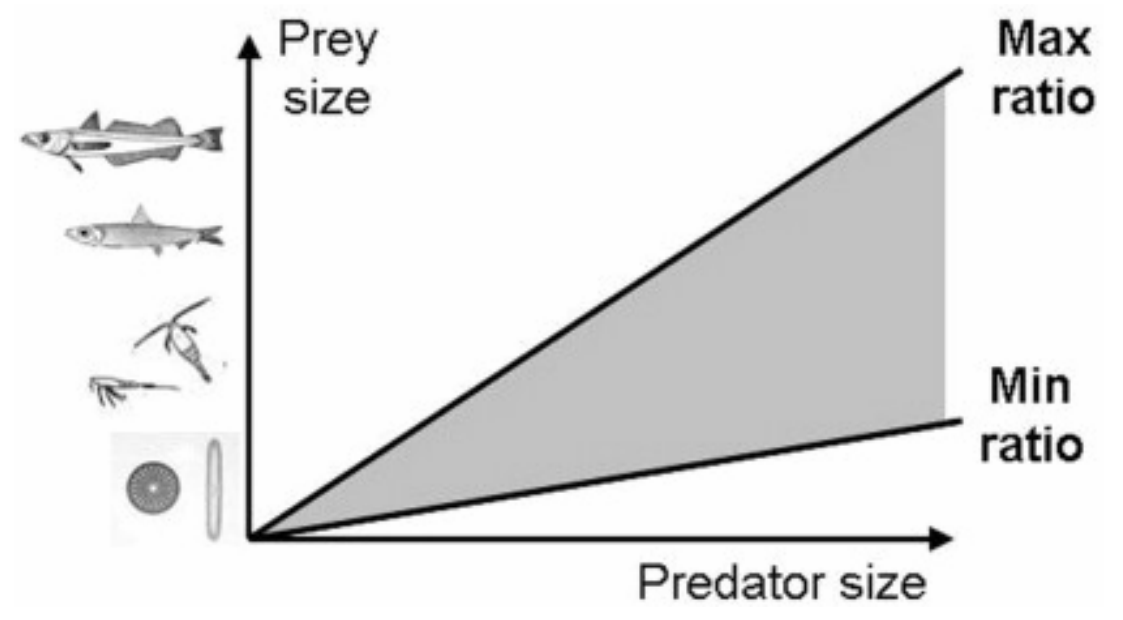

Figure S1: Feeding size range of fish modelled in Osmose. Fish can eat any prey comprised between a maximum and minimum size relatively to the predator size (grey area). Predation is opportunistic and therefore does not consider taxonomic preference, leading predator to feed indifferently on plankton or fish if their size is suitable. 


\section{Appendix A. Electronic supplements}

\section{The HTL model: OSMOSE}

In the 2 dimensional individual-based model (IBM) Osmose (Shin and Cury, 2001, 2004), the basic unit is a super-individual representing fish school of individuals of the same size, same location and belonging to the same species. The main assumption is that predation is opportunistic and size-based constrained, and therefore occurs when there are both spatio-temporal cooccurrence and size-adequation between a predator and its prey. In this application the time step is set to one month and includes the following processes:

- Spatial distribution: Schools are randomly distributed in the grid accordingly to input distribution information computed per species, age and per season. If the distribution map of the population does not change from one time step to the next, schools undergo a random walk.

- Natural mortality: The natural mortality term corresponds to mortality due to diseases, senescence and predation by organisms unrepresented in the model (e.g. birds and mammals).

- Predation: A fish school can prey on any organisms of suitable size (Figure S1), which are located in its own cell. The biomass of plankton available is computed from the plankton concentration (mmolN. $\mathrm{m}^{-3}$ ) using the following conversion factor:

$$
\text { conversion factor }=\frac{14 \mathrm{~g} \mathrm{~N}}{\text { mole } N} \cdot \frac{0,1 \mathrm{~g} \text { dry weight }}{g N} \cdot \frac{5 \mathrm{~g} \text { wet weight }}{g \text { dry weight }}
$$

The amount of prey eaten depends on its relative biomass (uniform predation) and on the maximum food edible by the predator (set to 3.5 grams of food per body gram annually, Shin and Cury 2001). At the end of this process a predation efficiency is calculated for each school as the ratio between the amount of prey eaten and the maximum biomass edible.

- Growth: After the predation stage, if the amount of food eaten is higher than the food requirement for maintenance, schools can grow following the von Bertalanffy model, with a length increase weighted by the predation efficiency.

- Starvation: In case of a ration lower than the required biomass for maintenance, fish school undergo a starvation mortality which reduces the number of individuals constituting the school.

- Fishing: A fishing mortality different for each species is applied to any school older than the recruitment age, according to a fishing seasonality.

- Reproduction: At the end of the time step, the reproduction consists in adding eggs in the model, calculated from the spawning biomass, a fecundity parameter and the spawning seasonality.

The Benguela application represents the dynamics of twelve fish species from small pelagic fish to large demersal fish in the 1990s (Shin et al., 2004; Travers et al., 2006). Theses species have been chosen according to their importance in terms of biomass, commercial interest and trophic interactions. These are anchovy (Engraulis encrasicolus), sardine (Sardinops sagax), redeye (Etrumeus whiteheadi), lanternfish (Lampanyctodes hectoris), lightfish (Maurolicus muelleri), shallow water hake (Merluccius capensis), deep water hake (Merluccius paradoxus), kingklip (Genypterus capensis), silver kob (Argyrosomus inodorus), snoek (Thyrsites atun), chub mackerel (Scomber japonicus) and horse mackerel (Trachurus $t$. capensis). They are all characterized in the model by specific life history traits (table A1). 
Table A1: Input parameters of the OSMOSE model for the 12 fish species modelled explicitly. $L_{\infty}, K$, and $t_{0}$ are the parameters of the von Bertalanffy growth model; $c$ is Fulton's condition factor and b the exponent of the L-W allometric relationship; $\varphi$ is relative fecundity; amat is age at maturity; amax is longevity; Mdivers is an additional mortality rate (resulting from predation by other species of the ecosystem that are not explicitly modelled); arec is age of recruitment; $F$ is the annual fishing mortality rate.

Growth

Reproduction

\begin{tabular}{|c|c|c|c|c|c|c|c|c|c|c|c|c|}
\hline \multirow[b]{2}{*}{ Species } & & \multicolumn{5}{|c|}{ Growth } & \multicolumn{2}{|c|}{ Reproduction } & \multicolumn{4}{|c|}{ Survival } \\
\hline & & $\begin{array}{l}\mathrm{L}_{\infty} \\
\mathrm{cm}\end{array}$ & $\begin{array}{l}\mathrm{K} \\
y^{-1}\end{array}$ & $\begin{array}{l}\mathrm{t}_{0} \\
y\end{array}$ & $\begin{array}{c}\mathrm{C} \\
\text { g.cm-3 }\end{array}$ & b & $\begin{array}{c}\varphi \\
\text { eggs. } g^{-1}\end{array}$ & $\begin{array}{c}\text { amat } \\
y\end{array}$ & $\begin{array}{c}\operatorname{amax} \\
y\end{array}$ & $\begin{array}{c}\text { Mdivers } \\
y-1\end{array}$ & $\begin{array}{c}\text { arec } \\
y\end{array}$ & $\begin{array}{c}F \\
y-1\end{array}$ \\
\hline Anchovy & Engraulis encrasicolus & 14.8 & 1.37 & -0.03 & 0.007 & 3 & 8000 & 1 & 5 & 0.403 & 1 & 0.23 \\
\hline Sardine & Sardinops sagax & 26 & 0.26 & -1.5 & 0.009 & 3 & 2400 & 2 & 10 & 0.365 & 1 & 0.16 \\
\hline Redeye & Etrumeus whiteheadi & 30.1 & 0.71 & 0.28 & 0.009 & 3 & 750 & 1 & 6 & 0.208 & 1 & 0.04 \\
\hline Lanternfish & Lampanyctodes hectoris & 7 & 1.66 & 0.06 & 0.008 & 3 & 646 & 0.5 & 2 & 0.226 & 1 & 0.0003 \\
\hline Lightfish & Maurolicus muelleri & 6 & 1.15 & 0.06 & 0.008 & 3 & 334 & 0.5 & 2 & 0.226 & 1 & 0.0003 \\
\hline Shallow water hake & Merluccius capensis & 270.6 & 0.039 & -0.73 & 0.006543 & 3.0425 & 500 & 4 & 15 & 0.228 & 3 & 0.23 \\
\hline Deep water hake & Merluccius paradoxus & 219.4 & 0.049 & -0.914 & 0.007846 & 2.9759 & 500 & 4 & 15 & 0.174 & 3 & 0.33 \\
\hline Kingklip & Genypterus capensis & 180 & 0.105 & 0.05 & 0.001 & 3 & 500 & 5 & 24 & 0.182 & 3 & 0.11 \\
\hline Silver kob & Argyrosomus inodorus & 116 & 0.12 & -1.47 & 0.007 & 3 & 150 & 2 & 25 & 0.228 & 3 & 0.181 \\
\hline Snoek & Thyrsites atun & 115.3 & 0.294 & -0.1 & 0.018 & 3 & 130 & 3 & 10 & 0.132 & 2 & 0.25 \\
\hline Chub mackerel & Scomber japonicus & 68 & 0.207 & -0.98 & 0.005 & 3 & 300 & 3 & 8 & 0.143 & 2 & 0.07 \\
\hline Horse mackerel & $\begin{array}{l}\text { Trachurus } \quad \text { trachurus } \\
\text { capensis }\end{array}$ & 54.5 & 0.183 & -0.65 & 0.009 & 3 & 250 & 3 & 8 & 0.314 & 2 & 0.06 \\
\hline
\end{tabular}

\section{Survival}


